\title{
Current status of the Mohave ground squirrel: an update covering the period 2013-2020
}

\section{PHILIP LEITNER*}

\begin{abstract}
Endangered Species Recovery Program, California State University, Stanislaus, One Uni-
\end{abstract} versity Circle, Turlock, CA 95382, USA

*Corresponding Author: pleitner@pacbell.net

The Mohave ground squirrel (Xerospermophilus mohavensis) is endemic to the western Mojave Desert of California. It is restricted to a small geographic area and is listed as Threatened under the California Endangered Species Act. Human development has resulted in loss and degradation of its desert habitat and climate change is believed to pose an additional threat. To determine its current conservation status and geographic distribution, I have assembled all available data from field studies during the years 2013-2020. These data confirm that the species is still present in 4 core areas and that it continues to be widespread in the northern and central portions of its historical range. However, the recent data also confirm earlier conclusions that the Mohave ground squirrel is now extirpated from the southernmost portion of its range. Recent surveys raise concerns about its status in other areas as well. A large-scale trail camera survey on the South Range unit of China Lake Naval Air Weapons Station in 2019 failed to detect the Mohave ground squirrel over much of this large installation. Recent trail camera surveys on Fort Irwin strongly suggest that the closely-related round-tailed ground squirrel (Xerospermophilus tereticaudus) has now replaced the Mohave ground squirrel over most of the base. There is additional evidence that the round-tailed ground squirrel is present in disturbed habitats to the west of Barstow and that hybridization with the Mohave ground squirrel is occurring there. It will be important to protect and conserve currently occupied Mohave ground squirrel habitat in view of this new information.

Key words: climate change, conservation, distribution, Mohave ground squirrel, Mojave Desert, renewable energy, threats, Xerospermophilus mohavensis

The Mohave ground squirrel (Xerospermophilus mohavensis) is found only in a small area of the western Mojave Desert and is designated as a Threatened species under the California Endangered Species Act (CESA). It was one of the first species listed by the State of California, in 1971. While its historical range was about $20,000 \mathrm{~km}^{2}$, the Mohave ground squirrel is believed to occupy only about 65 percent of this area today. Mohave ground squirrels are only active aboveground in spring and early summer. As temperatures 
rise and desert vegetation dries out in June and July, they accumulate body fat and then enter a lengthy dormancy (Best 1995). They emerge in February and, if conditions are right, females raise litters of 6-10 young. Mohave ground squirrel reproduction is extremely sensitive to year-to-year variations in winter rainfall. If winter rainfall is low, new growth of desert annual vegetation is much reduced and Mohave ground squirrels will fail to reproduce (Harris and Leitner 2004; Leitner et al. 2017). Thus, their abundance is greatly reduced during multi-year droughts. The species may be severely affected if climate change results in hotter and drier conditions in the California deserts (Inman et al. 2016). Human activities have already resulted in substantial loss and degradation of suitable habitat for the species (Inman et al. 2013). The California Department of Fish and Wildlife (CDFW) recently completed a conservation strategy for the Mohave ground squirrel that summarizes the available scientific information for the species and lays the foundation for its conservation and recovery (CDFW 2019).

In recent years, there has been great interest in the development of renewable energy in the California deserts. In 2016, the U.S. Bureau of Land Management (BLM) approved the Desert Renewable Energy Conservation Plan (DRECP) that streamlined the permitting process for solar, wind, and geothermal projects while providing for the conservation and management of native species on public lands (U.S. Bureau of Land Management 2016). BLM has identified 3 Development Focus Areas (DFA) within the Mohave ground squirrel range and has funded field studies to document the status of the species both in the DFAs and elsewhere in its range. Since 2013 there have also been 33 surveys on private lands proposed for solar development.

I have published two previous studies of the status of the Mohave ground squirrel throughout its range. The first report assembled data from all available sources covering the period 1998-2007 (Leitner 2008). These data strongly suggested that the species was absent from much of the southernmost portion of its historical range. The second study reviewed new information from 2008-2012, confirming this conclusion and also pointing to the lack of adequate data on the status of the species on two large military installations: Naval Air Weapons Station China Lake (China Lake) and Fort Irwin National Training Center (Fort Irwin) (Leitner 2015). The objectives of this paper are to (1) summarize information on Mohave ground squirrel occurrence from the period 2013-2020, and (2) synthesize this information to assess the current status and distribution of this species. This information can then be used to inform conservation actions for the Mohave ground squirrel.

\section{METHODS}

I have assembled and analyzed all available data pertaining to Mohave ground squirrel distribution and occurrence over the 8-year period from 2013 through 2020. These data include 1) records from the California Natural Diversity Database (CNDDB), 2) protocol trapping efforts required for proposed development projects, 3) reports from regional field studies sponsored by government agencies, and 4) incidental observations reported by field biologists. The closely-related round-tailed ground squirrel (Xerospermophilus tereticaudus) is widely-distributed through the eastern California deserts (Ernest and Mares 1987). It occurs in a number of locations along the eastern boundary of the Mohave ground squirrel range. Therefore, I have also collected recent occurrence data for this species along this contact zone.

The CNDDB is a state-wide inventory of the status and geographic locations of 
special-status plants, animals, and natural communities. This online catalog is managed and regularly updated by CDFW. It provides positive records of occurrence only. Prior to 2013 the CNDDB listed 414 Mohave ground squirrel records and 20 new occurrences were entered during the period 2013-2020. These new occurrences have been recorded and mapped for this status update.

The CDFW requires that live-trapping surveys be conducted at proposed development sites within or adjacent to the range of the Mohave ground squirrel where suitable habitat is present. These surveys must follow a specific protocol and must be conducted by a qualified biologist who is permitted under a Memorandum of Understanding (MOU) with CDFW (CDFG 2003). Protocol surveys generally require 5 days of trapping on 100-trap grids. They must be repeated 3 times during the Mohave ground squirrel active period. All MOU-holders must file annual reports describing the results of any protocol surveys that they have carried out. I was able to access these reports and have incorporated the results of 218 protocol surveys into this status update. All protocol surveys were conducted on private land. They were concentrated in the southern and western portions of the historical range and were often required for proposed solar and utility projects.

During the past 8 years, a number of regional field investigations yielding important data on Mohave ground squirrel distribution and status have been sponsored by state and federal agencies. These surveys are conducted on public and military lands and are intended to support management and conservation actions. They have employed both live-trapping and camera-trapping techniques. Live-trapping efforts generally utilize grids of 100 traps and are conducted over 5 consecutive days. Sampling procedures for camera-trapping studies have been more variable, with 5-25 cameras per site and sampling periods ranging from 5-15 days. In 2013 and 2014, camera-trapping studies funded by CDFW helped to clarify the status of the Mohave ground squirrel on the western edge of its range in Kern County (Leitner 2014, Leitner and Delaney 2015). The Bureau of Land Management has supported extensive live-trapping and camera-trapping surveys from 2016-2020 in several important areas (Leitner 2020). These included the Little Dixie Wash and Coolgardie Mesa core areas, 3 Development Focus Areas, and the contact zone west of Hinkley where round-tailed ground squirrels have been recorded. In 2018, Edwards Air Force Base (EAFB) conducted camera-trapping at 25 sites to review the current status of the species at the installation (Lopez and Tautfest 2019). China Lake carried out an extensive camera-trapping survey in 2019 at 25 locations on its South Range, a large area where Mohave ground squirrel data were completely lacking (Vernadero Group Incorporated 2019).

I have also obtained 25 incidental Mohave ground squirrel records. These records are based on reports from biologists who have made visual observations or have detected them with traps or trail cameras incidental to other field activities.

I list the number of records obtained for this review from all 4 data sources (Table 1). For regional and protocol live-trapping surveys, a record was defined as a single trapping session (usually 5 days) at a specific grid location. A positive record refers to a 5-day trapping session in which one or more Mohave ground squirrels were captured. For regional camera-trapping surveys, a positive record means that at least one Mohave ground squirrel photograph was obtained during the sampling period, which can range from 5 to 15 days. Of course, all incidental records are positive. 
Table 1. A summary of the data sources used in this 2013-2020 status review of the Mohave ground squirrel. Regional surveys are conducted on public and military lands and are sponsored by government agencies to collect data needed for management, while protocol surveys are carried out on private lands proposed for development to determine presence or absence of Mohave ground squirrels. Incidental observations are Mohave ground squirrel records obtained by qualified biologists incidental to other field investigations. A record represents a unique survey event; for live-trapping surveys the usual time period was 5 days, while camera-trapping surveys ranged from 5-15 days. The total number of records of each type is presented, along with the number of surveys that resulted in the detection of one or more Mohave ground squirrels. The sampling effort is indicated as trap-days, that is, the number of live-traps or camera traps used in a survey multiplied by the number of days that traps were operated.

\begin{tabular}{lccc}
\hline Type of Data & Total Records & Positive Records & Trap-Days \\
\hline Regional Live-Trapping Surveys & 124 & 59 & 85,217 \\
Regional Camera-Trapping Surveys & 137 & 76 & 29,168 \\
Protocol Live-Trapping Surveys & 218 & 14 & 118,775 \\
Incidental Observations & 25 & 25 & --- \\
Totals & 504 & 174 & 233,094 \\
\hline
\end{tabular}

\section{RESULTS}

\section{General Distribution}

A great deal of new information on Mohave ground squirrel status and distribution has become available over the past 8 years. Figure 1 shows the general spatial pattern of both positive and negative records throughout the species range. The 4 core areas shown here were first identified in Leitner (2008) based on evidence that they had historically supported relatively abundant and widespread Mohave ground squirrel populations. Since 2013, Mohave ground squirrels have been detected in all 4 core areas (Fig. 1).

Survey data are available for most areas, except for the North Range of China Lake and for the area between Ridgecrest and Red Mountain. As in previous status reviews, regional trapping and camera surveys have yielded the greatest proportion of positive records (Leitner 2008, 2015). The most recent protocol surveys did not detect the species and were concentrated in the southern part of the range where there is more private land available for development (Table 1). The number of protocol surveys was much reduced as compared to the 1998-2012 period, but there has been increased use of cameras to supplement live trapping in these project-related surveys.

In general, the new data confirm the patterns documented in the 2 previous status reviews (Leitner 2008, 2015). There have been no recent occurrence records outside the historical range boundaries (Fig. 1). Furthermore, there continues to be clear evidence that Mohave ground squirrels are no longer present in large areas within the historical range. This is particularly striking in the southernmost part of the range where there are essentially no records from northeastern Los Angeles County and Lucerne Valley, with only a single detection near Victorville. A number of protocol, regional, and camera surveys have failed to detect the species on the western portion of Edwards Air Force Base or around the town of Mojave, as was noted for the period 2008-2012 (Leitner 2015). New camera data from Fort Irwin have revealed that round-tailed ground squirrels are now present on much of this military reservation, well within the historical Mohave ground squirrel range boundary. A 


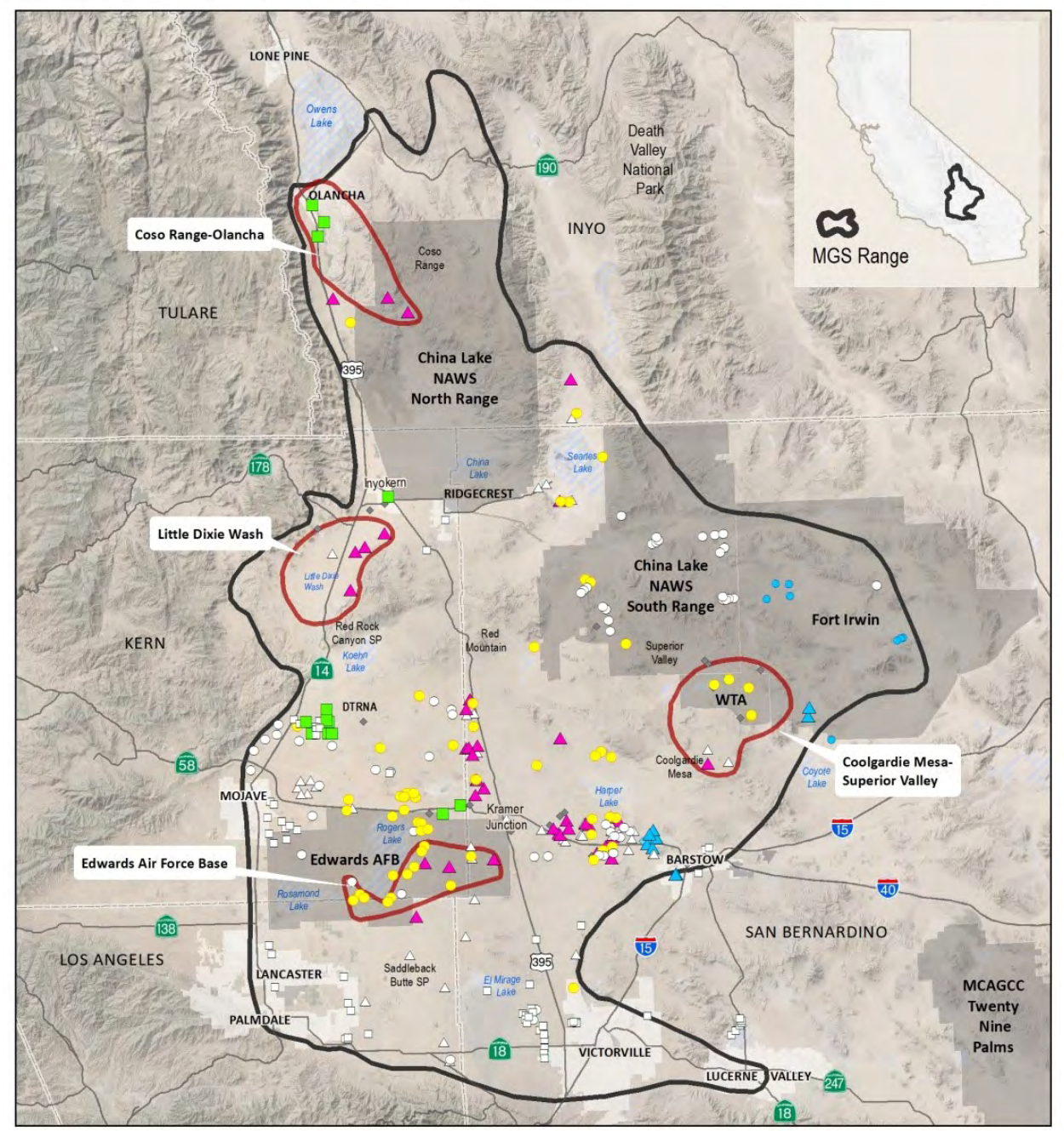

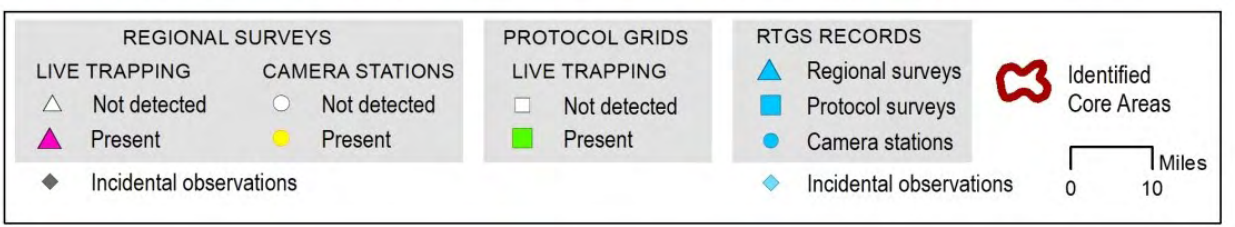

Figure 1. The geographic distribution of all Mohave ground squirrel records for the period 2013-2020. The solid black line denotes the historical boundary of the Mohave ground squirrel range. The 4 core areas outlined here continue to support Mohave ground squirrel populations. Occurrences of the round-tailed ground squirrel (RTGS) in the contact zone between the 2 species are also shown.

recent large-scale camera survey on the South Range unit of China Lake has failed to record Mohave ground squirrels over most of this large facility (Vernadero Group Incorporated 2019). The only positive records were found at a few sites on its extreme southern and western edges. 


\section{Regional Analysis}

Inyo County. - The northernmost portion of the Mohave ground squirrel range is located in Inyo County just east of the Sierra Nevada (Fig. 2). Most of this area is made up of public lands administered by the US Bureau of Land Management (BLM) and military test ranges of China Lake. As in previous years, the species was captured regularly at 2 longterm monitoring sites in the Coso Range on China Lake (Leitner 2019). No surveys were undertaken elsewhere on the North Range unit of China Lake, so the status of the species is unknown over this extensive area. Mohave ground squirrels were detected regularly at 2 locations on public land in Rose Valley, which BLM has identified as the Haiwee Development Focus Area for geothermal energy under the DRECP. Protocol trapping at 3 proposed development sites near Olancha resulted in Mohave ground squirrel captures, demonstrating that the species is still extant at the historical northwestern corner of its range. To the east in Searles Valley, Mohave ground squirrels were detected at 2 locations, confirming that the species is still present in this area as well.

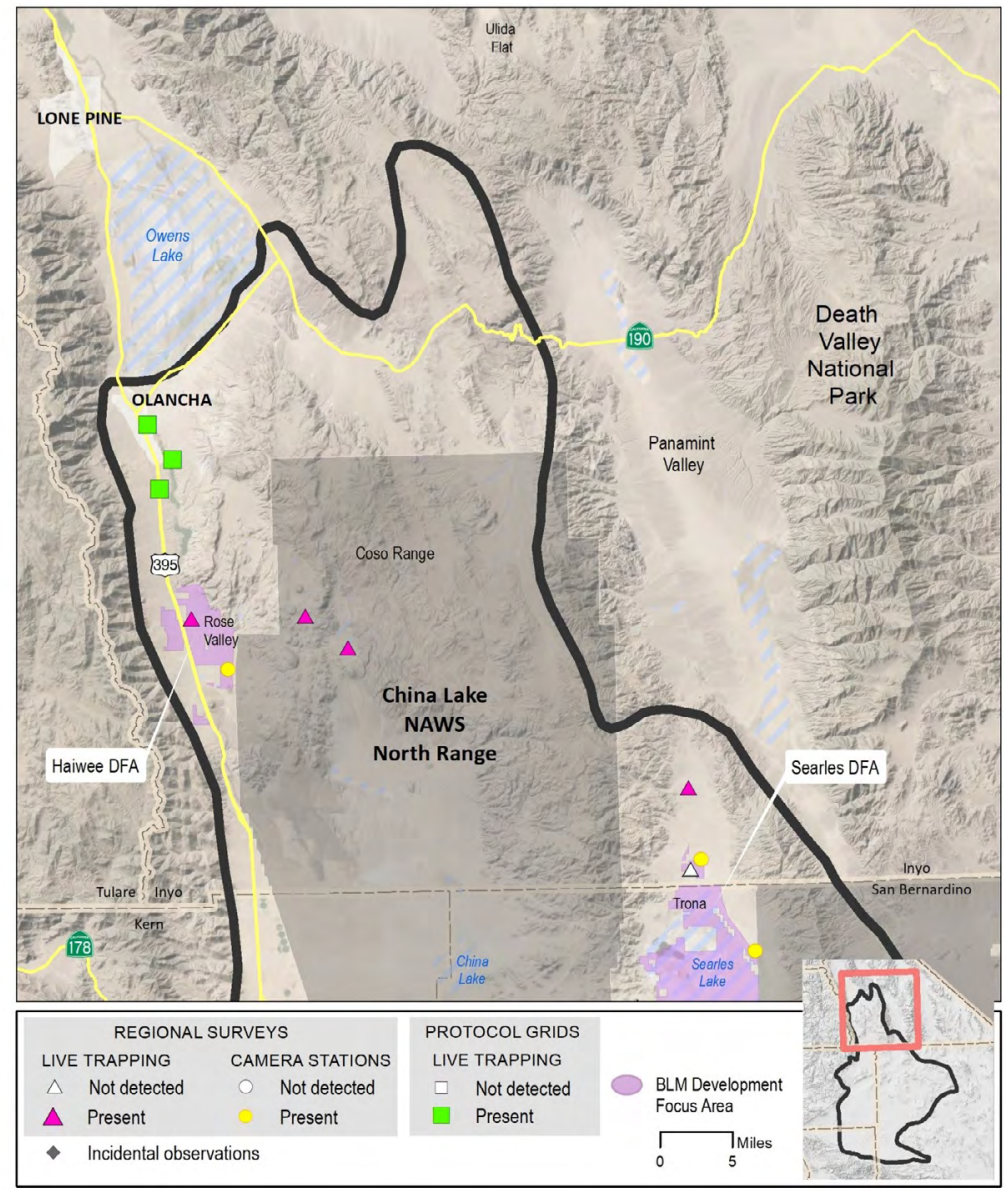

Figure 2. Mohave ground squirrel range within Inyo County, California. Symbols indicate locations of 2013-2020 records, both positive and negative. 
Kern County - Ridgecrest area, Searles Valley, and Little Dixie Wash. There is little evidence regarding the status of the Mohave ground squirrel in the Ridgecrest area during the period 2013-2020 (Fig. 3). Protocol trapping was carried out at 3 sites in this region and the species was detected only at one location near Inyokern. BLM has designated a large portion of Searles Valley as a DFA; Mohave ground squirrels were detected at 4 study sites on the margins of this proposed development area. There are no positive records available from south of Ridgecrest through the Spangler Hills Off-Highway Vehicle Area to Red Mountain and Fremont Valley.

The broad valley to the southwest of Inyokern known as Little Dixie Wash has been identified as a core area (Leitner 2008). Monitoring was conducted there by live-trapping at 4 regional survey sites from 2016-2019 (Leitner 2020). Mohave ground squirrels were present at 3 of the 4 sites, although numbers were quite low. The species was also documented in 2015 at a CDFW Ecological Reserve a few kilometers southwest of Inyokern.

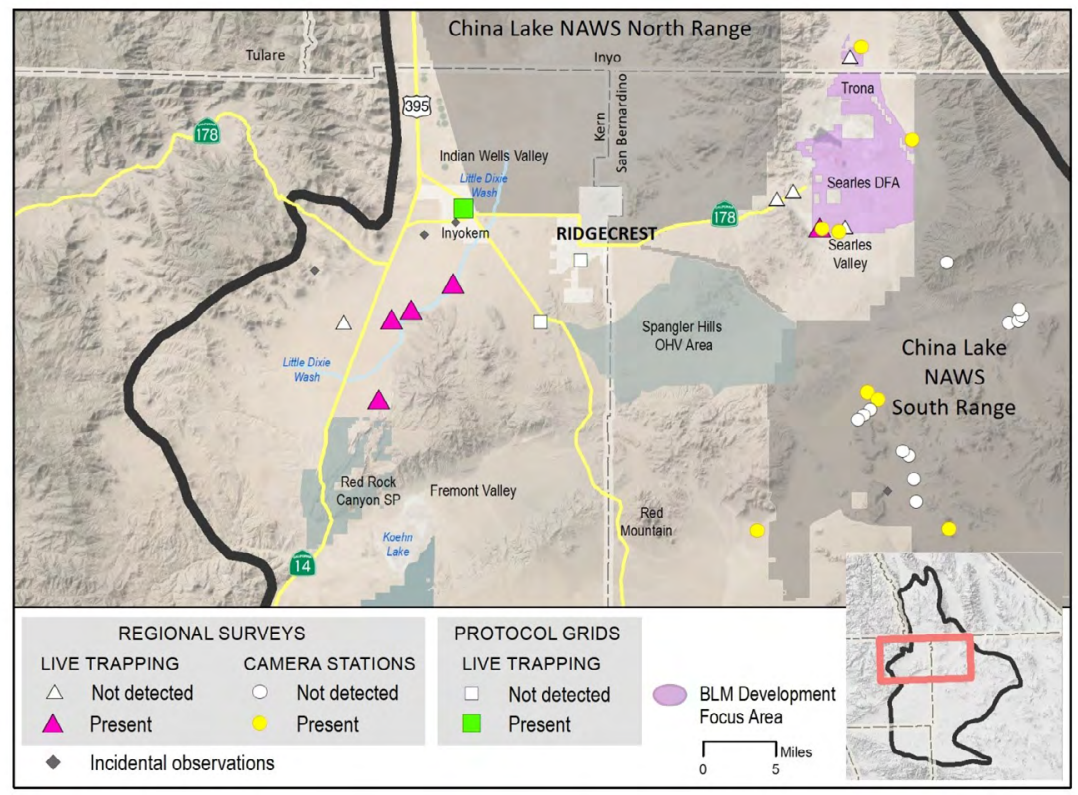

Figure 3. Mohave ground squirrel range in the vicinity of Ridgecrest, Searles Valley, and in the Little Dixie Wash region. Symbols indicate locations of 2013-2020 records, both positive and negative.

Kern County-Fremont Valley to Edwards Air Force Base. Five large-scale studies have been carried out in the region from Fremont Valley south to Edwards Air Force Base (EAFB). In 2013 and 2014, CDFW sponsored camera studies here that sampled 15 sites dispersed throughout the area. Most of the study sites were on BLM land, with a few on private and CDFW properties. Mohave ground squirrels were detected at only 4 locations, all to the east and south of California City (Fig. 4). The BLM has funded a major sampling effort in the North of Kramer DFA. This project has collected data from 2018 through 2020 on 4 trapping grids and 4 camera sites located on BLM lands throughout this DFA. Mohave ground squirrels have been documented at all 8 of these sampling units (Fig. 4). Finally, 2 protocol surveys using both live-trapping and camera trapping have detected the 


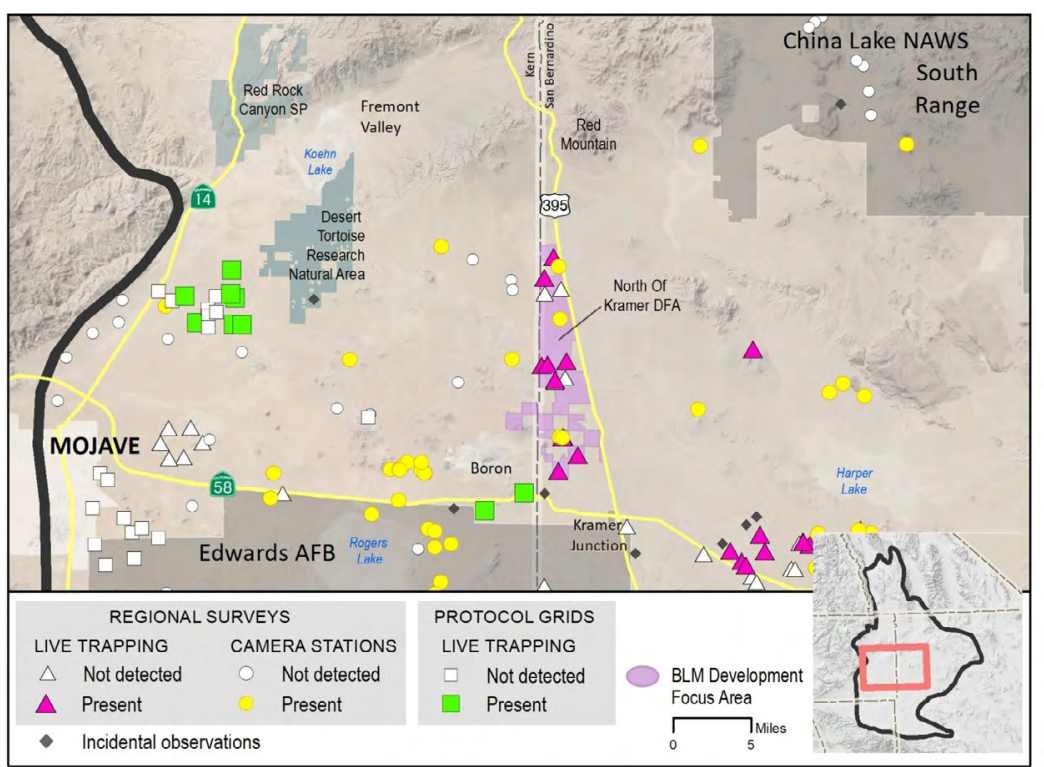

Figure 4. Mohave ground squirrel range extending from Fremont Valley and Red Mountain to Edwards Air Force Base. Symbols indicate locations of 2013-2020 records, both positive and negative.

species on potential development parcels west of the Desert Tortoise Research Natural Area (DTRNA) in 2019 and 2020. The DTRNA is a fully-protected conservation area located between Fremont Valley and Edwards Air Force Base and is known to support a significant Mohave ground squirrel population. It will be important to conserve population linkages between the DTRNA and EAFB.

San Bernardino County - Coolgardie Mesa and Superior Valley, San Bernardino County. Mohave ground squirrels were first documented on this extensive plateau north of Barstow through pioneering field work by Wessman (1977). Leitner (2008) reviewed a number of subsequent field studies in this region and proposed it as a core area based upon extensive occurrence records over a number of years. Live-trapping was carried out at 3 regional survey sites on Coolgardie Mesa from 2016-2019 (Leitner 2020). Although Mohave ground squirrels had been found at those locations during previous field studies (Scarry et al. 1994; Leitner 2010), the species was present at only one of the 3 sites during this recent trapping effort (Fig. 5). Most of Superior Valley in the northern portion of this core area has been incorporated into Fort Irwin and is now known as the Western Training Area (WTA). Camera monitoring in 2015 and 2016 by Fort Irwin environmental staff showed that Mohave ground squirrels were present at 5 sites throughout the WTA (Fig. 5).

San Bernardino County - China Lake South Range and Fort Irwin. I noted in the most recent status report (Leitner 2015) that data on the species were lacking for much of China Lake and Fort Irwin. Recent trail camera surveys have helped to clarify Mohave ground squirrel distribution on these 2 large military installations. In 2019, China Lake sponsored an extensive study at 25 locations throughout the very large South Range unit (Vernadero Group Inc. 2019). The species was detected at only 3 of these sites, all in the southwestern corner of the South Range (Fig. 5). Incidental observations during this project documented Mohave ground squirrels at a location near the camera detections and also in Superior Valley close to older records on the Fort Irwin WTA. 


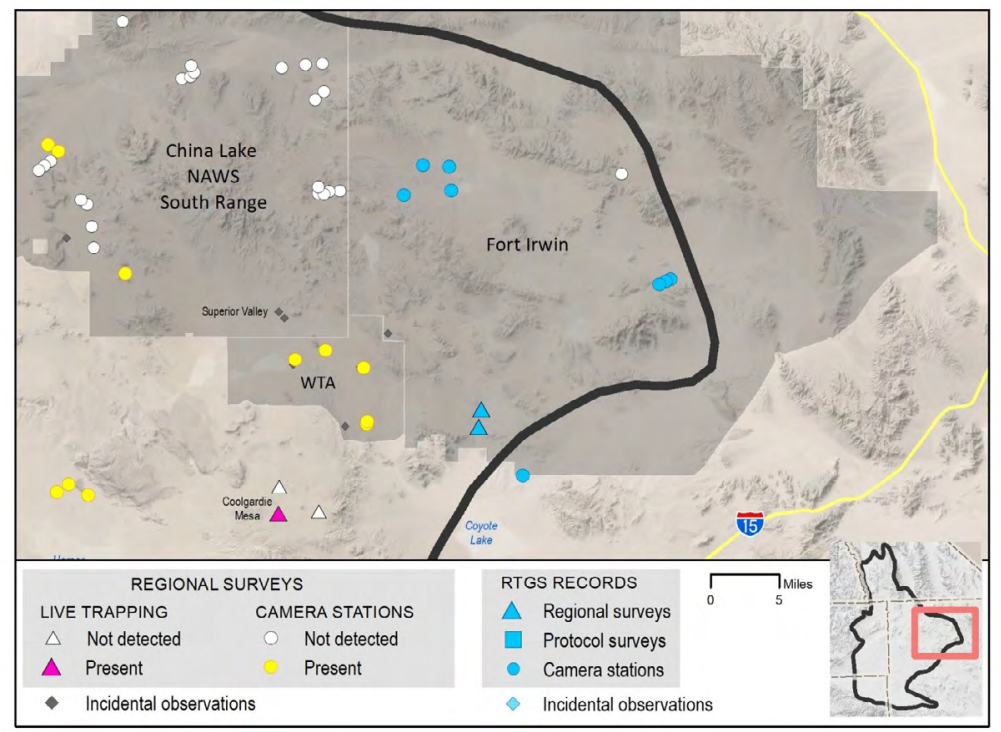

Figure 5. Mohave ground squirrel range from Coolgardie Mesa north to Fort Irwin and South Range of China Lake. Symbols indicate locations of 2013-2020 records, both positive and negative. Round-tailed ground squirrel (RTGS) records are also shown.

Camera studies were undertaken on Fort Irwin in 2018 in a region near the western boundary that had been proposed for a large training facility. This work documented the presence of round-tailed ground squirrels at a number of camera sites here (Fig. 5). This discovery was quite unexpected, as the area is approximately $30 \mathrm{~km}$ west of the historical eastern boundary of the Mohave ground squirrel range. Other recent camera results from an area on the north side of the Tiefort Mountains provide further evidence of round-tailed ground squirrel occupancy throughout much of Fort Irwin with the important exception of the WTA.

Kern County - Edwards Air Force Base. A large portion of EAFB was identified as a core area by Leitner (2008) based upon a number of Mohave ground squirrel records to the east and south of Rogers Dry Lake. The importance of this area has been confirmed by additional monitoring studies in recent years (Leitner 2015). In 2018, EAFB sponsored a camera-trapping survey at 25 sites (Lopez and Tautfest 2019) that has again documented the presence of the species throughout the eastern portion of the base (Fig. 6). However, it seems clear that that the western portion of EAFB does not support a Mohave ground squirrel population. A number of surveys since 1998 have consistently failed to detect the species there (Leitner 2008; Leitner 2015).

San Bernardino County - Kramer Junction to Barstow. There are a number of recent records of Mohave ground squirrels to the east of Kramer Junction, generally confirming that this area continues to support a widely distributed population (Fig. 7). However, trapping studies in the vicinity of Hinkley in 2013 resulted in the capture of round-tailed ground squirrels at several locations, a result confirmed by genetic analysis (Leitner et al. 2017). Since 2016, the BLM has sponsored extensive live-trapping and camera surveys in the region to the west of Hinkley to clarify the status of the Mohave ground squirrel there. It appears that this species is present at 12 sites here, although there is genetic evidence that hybridization with round-tailed ground squirrels is occurring here as well (Leitner and Leitner 2017). 


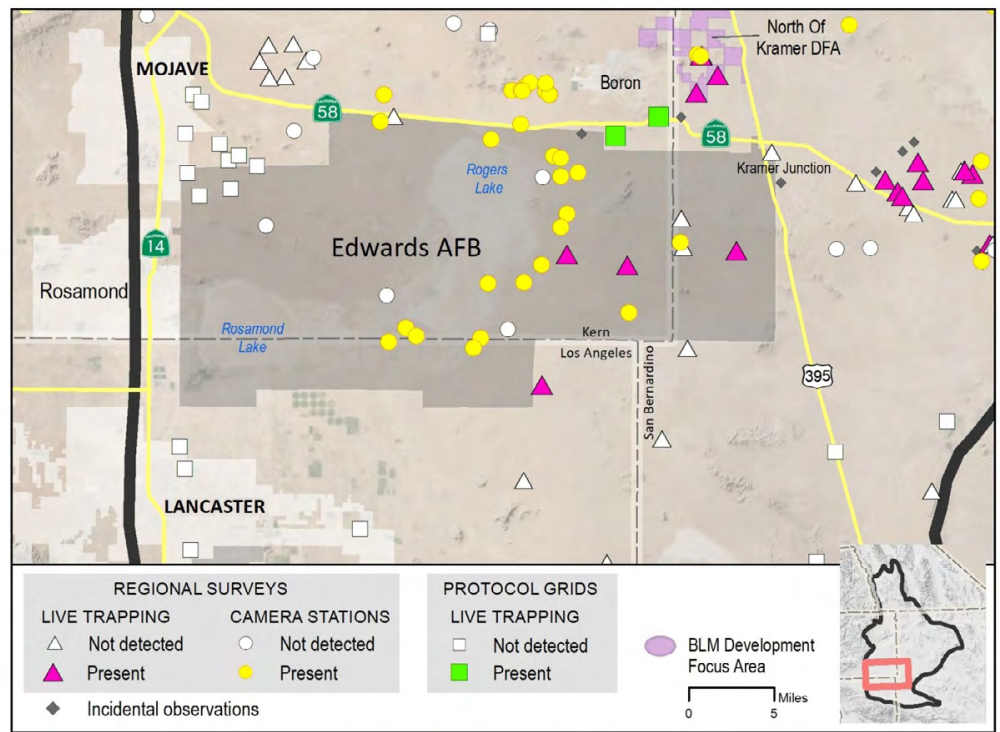

Figure 6. Mohave ground squirrel range on Edwards Air Force Base and vicinity. Symbols indicate locations of 2013-2020 records, both positive and negative.

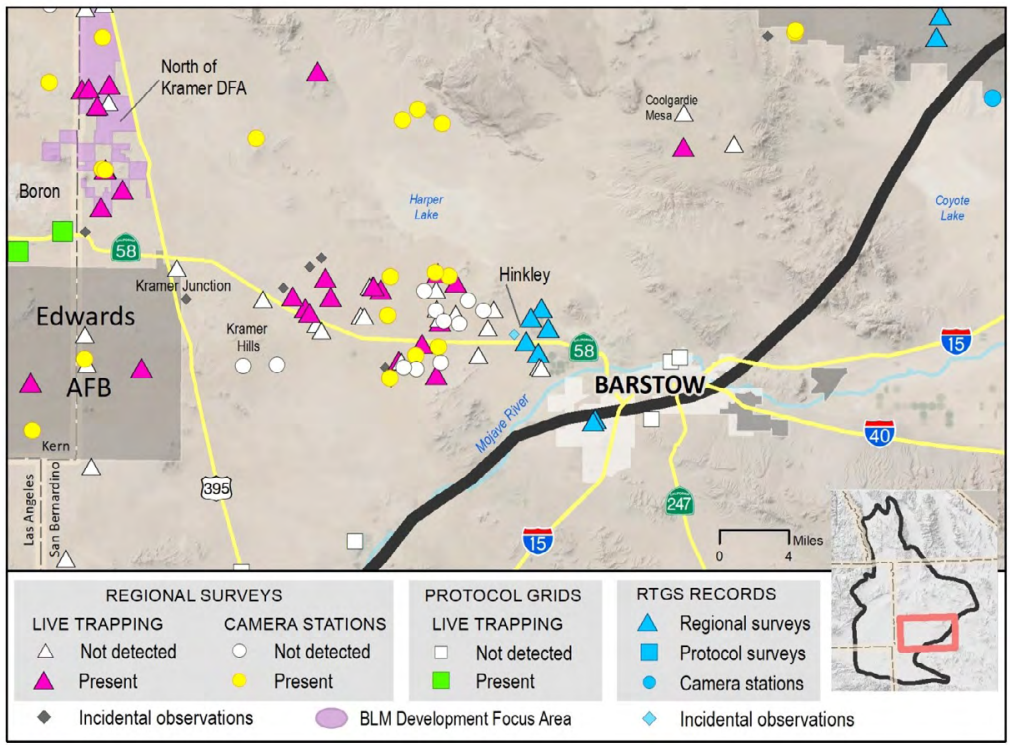

Figure 7. Mohave ground squirrel range from Kramer Junction east to Barstow. Symbols indicate locations of 2013-2020 records, both positive and negative. Round-tailed ground squirrel (RTGS) records are also shown. 
Los Angeles County.-Protocol and regional trapping efforts since 2013 have largely failed to document Mohave ground squirrel occurrence in Los Angeles County. There have been only 5 recent occurrences in the extreme northeastern corner of the county, on or adjoining EAFB (Fig. 8). These results are consistent with all survey efforts in recent years, strongly suggesting that the species is essentially extirpated in Los Angeles County (Leitner 2008; Leitner 2015).

San Bernardino County-Mojave River to Lucerne Valley. The Mojave River from Barstow to Victorville has historically been considered the eastern boundary of the Mohave ground squirrel range, with an easterly extension from Victorville to Lucerne Valley. There is no recent evidence that the species is present to the east of this reach of the Mojave River. Protocol surveys since 2013 in Barstow, Apple Valley, and Lucerne Valley have failed to detect Mohave ground squirrels, although round-tailed ground squirrels continue to be documented in the area around Barstow (Fig. 9).

San Bernardino County - Victor Valley. A great deal of urban development has occurred in the Victorville region during the past few decades, resulting in a current human population of approximately 400,000 . Since 1998 , protocol surveys have yielded only a few Mohave ground squirrel detections in this region. In June 2020, a camera trap captured the first record of the species here since 2011 (Fig. 9). Thus, there still appears to be a relict population in Victor Valley, but it is difficult to determine its exact status and geographic extent because almost all land there is in private ownership.

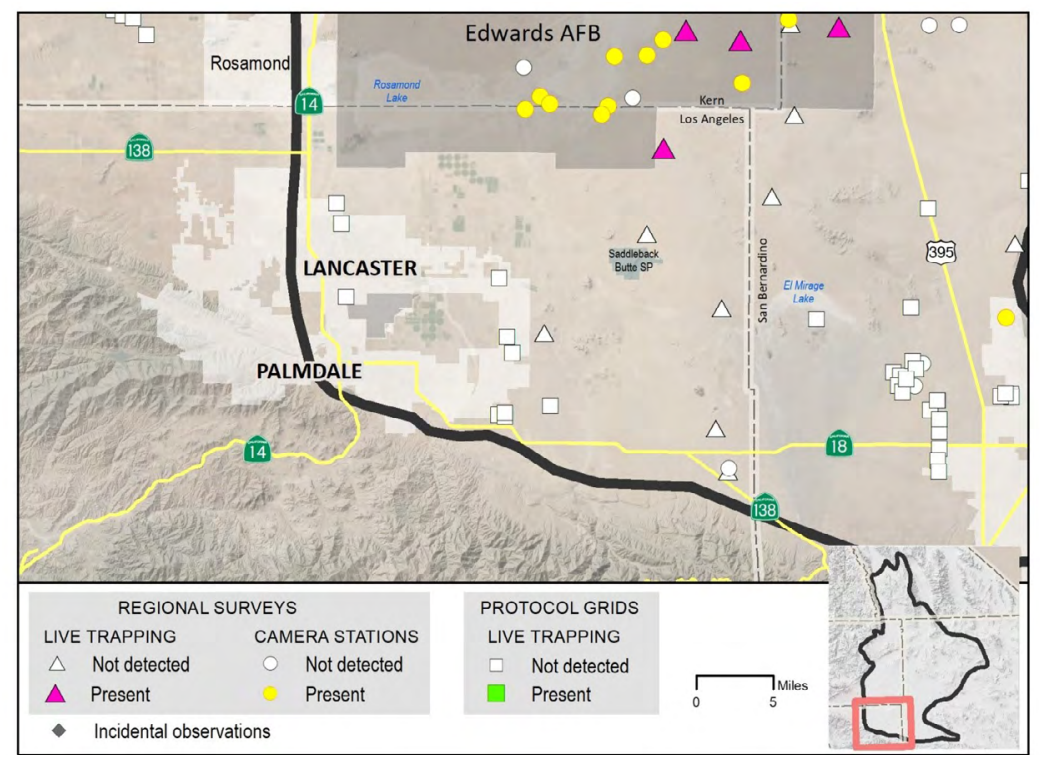

Figure 8. Mohave ground squirrel range in Los Angeles County, California. Symbols indicate locations of 2013-2020 records, both positive and negative. 


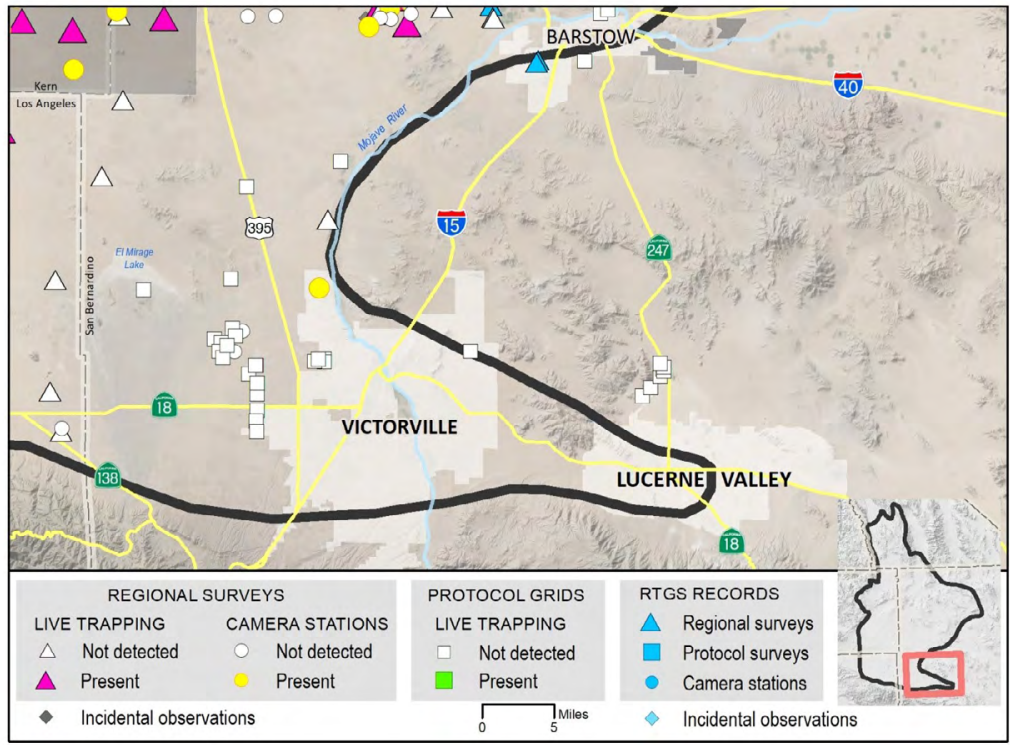

Figure 9. Mohave ground squirrel range from Barstow to Victor Valley. Symbols indicate the locations of 2013-2020 records, both positive and negative. Round-tailed ground squirrel (RTGS) records are also shown.

\section{DISCUSSION}

\section{Current Geographic Distribution}

The boundaries of the range map (Fig. 1) provide the best representation of the historical Mohave ground squirrel distribution. Data for the period 2013-2020 show that the species is present throughout much of the northern and central portions of the historical range. The 4 core areas as mapped in Leitner (2008) still support extant Mohave ground squirrel populations (Fig. 1). Live-trapping and camera studies have also documented widespread populations in all 3 of the DFAs: Haiwee, Searles, and North of Kramer. There are also a number of recent records east of Kramer Junction along the SR58 corridor and in the vicinity of the DTRNA near California City. However, since 2013 there have been few documented records for the North Range of China Lake and for the public lands from Ridgecrest south to Red Mountain (Figs. 2 and 3). These areas should be a priority for future surveys to determine the status of the species there.

There is substantial evidence that Mohave ground squirrel populations are absent or critically diminished in several geographic areas within the historical range. In particular, the species appears to be extirpated from the southernmost portions of the range. The core area on EAFB is the only portion of the southernmost range that continues to support a widespread population. According to the CNDDB, there were numerous records of the species throughout northeastern Los Angeles County in the 1970s and 1980s; however, the species has been almost completely absent from this entire region since 1991. The only current records from Los Angeles County are on or extremely close to EAFB. The recent large-scale camera study on EAFB has again confirmed that the species is not present on 
the western portion of this large military installation (Lopez and Tautfest 2019). A single camera detection in Victor Valley in 2020 provides the only evidence of an extant population in that part of the historical range. All protocol surveys here since 2011 failed to capture or observe the species. Because the region consists almost entirely of private land, it is very difficult to conduct regional surveys that might identify potential conservation opportunities for this relict population.

Recent camera studies on military bases in the northern parts of the range also indicate that the species may be absent from significant areas within the historical range boundaries. Mohave ground squirrels were not detected at 22 of 25 camera sites on the China Lake South Range and were documented only along the southern edge of this large installation (Vernadero Group Inc. 2019). There is now evidence from camera data that round-tailed ground squirrels have replaced Mohave ground squirrels over almost all of Fort Irwin, a region where the latter were widely distributed in the 1990s (Krzysik 1994). In addition, live-trapping and genetic analyses have demonstrated that a round-tailed ground squirrel population is established west of Barstow in the Hinkley Valley (Leitner et al. 2017).

In conclusion, there is now concerning evidence that Mohave ground squirrels are absent from significant areas within the historical range. While the area of the historical range has been estimated at $\sim 20,000 \mathrm{~km}^{2}$, it appears that only slightly more than 13,000 $\mathrm{km}^{2}$ are potentially occupied.

\section{Threats}

In the decades prior to the economic crisis of 2008, there was a significant amount of Mohave ground squirrel habitat loss due to urban development, especially in the southern part of the range. The number of protocol surveys for development projects on private land provides an index of development pressure. There was an average of 110 protocol surveys per year during the 15-year period from 1998-2012. Since 2013 there has been an average of only 22 protocol surveys per year, a clear indication that residential and commercial development activity is much reduced.

However, in recent years there has been a great deal of interest in developing renewable energy resources in the California deserts. The important wind resource area near the town of Mojave saw significant expansion on private land beginning about 2006 and continuing until about 2012. These projects were all located to the west of and outside of the Mohave ground squirrel historical range boundary and protocol surveys have never detected the species there. However, there have also been a number of large solar projects proposed on private land within the Mohave ground squirrel range. Protocol surveys were conducted at potential solar sites near Lancaster and Victorville but, as expected, the species was not detected. On the other hand, Mohave ground squirrels have been found at proposed solar projects near the DTRNA, which is well-known to support a viable population. Such development can be permitted if adequate mitigation is provided, usually in the form of dedicated conservation land.

The DRECP identified 3 sites on public land within the Mohave ground squirrel range as DFAs (US Bureau of Land Management 2016). The BLM has sponsored multi-year livetrapping and camera studies at these sites. The results of this research will be evaluated in 2021 to inform decisions about leasing these areas for development of renewable energy. Thus far, the evidence suggests that both the North of Kramer and Haiwee DFAs provide good Mohave ground squirrel habitat and support healthy populations (Leitner 2020). On 
the other hand, the Searles DFA includes marginal habitat surrounding a saline playa. Mohave ground squirrels have been detected by camera trapping in a small isolated area at the north end of the DFA and there have been a few records of dispersing juveniles at the other margins of the DFA. Development of this DFA would have minimal impact on the species.

Approximately one-third of the historical Mohave ground squirrel range is located on large military reservations. Testing and training activities at EAFB and China Lake do not involve extensive ground operations, so there is relatively little impact to biological resources. In contrast, the mission at Fort Irwin is focused on realistic training of ground forces, which has resulted in considerable environmental impact. There are many Mohave ground squirrel records on Fort Irwin from 1973 through the mid-1990s (Krzysik 1994), but recent evidence indicates that round-tailed ground squirrels are now found throughout much of the facility. Round-tailed ground squirrels appear to be more tolerant of disturbance than Mohave ground squirrels, so military training activities may have favored their expansion. Public lands that make up a portion of the Coolgardie Mesa-Superior Valley core area were transferred to Fort Irwin a number of years ago. This area is now known as the Western Training Area and plans are being developed for training activities here. There could be significant impacts to an important Mohave ground squirrel population, depending upon the nature and location of military usage.

There is a growing consensus that climate change will result in continuing long-term warming and drying in the Southwestern deserts (Williams et al. 2020). Recent evidence from studies of desert faunal communities suggests that climate change is already having significant impacts. Iknayan and Beissinger (2018) undertook an extensive analysis of changes in the Mojave Desert avian community over the past century. Their analysis concluded that climate change, especially a long-term decline in rainfall, was the primary driver of a significant collapse in the species richness of Mojave Desert avian communities.

The Mohave ground squirrel appears to be highly susceptible to the predicted impacts of climate change in the Mojave Desert. Multi-year data from the Coso study area indicates that reproduction there occurs only when winter precipitation exceeds the threshold of 65 $\mathrm{mm}$ that appears necessary for the production of adequate spring herbaceous vegetation (Harris and Leitner 2004). The Mojave Desert underwent a prolonged drought from 19891991 and there was no reproduction in the Coso Mohave ground squirrel population for 2 years, resulting in severe population decline. It seems possible that the disappearance of Mohave ground squirrel populations throughout much of the southern range after 1991 was related to this drought. The overall effects of the more recent 2012-2016 drought are unclear. The species appears to still be present in all 4 core areas, although abundance may be somewhat lower (Leitner 2020).

\section{Conservation Needs}

A number of actions will be required to adequately meet the conservation needs of the Mohave ground squirrel. These include 1) continuing field studies to document patterns of occurrence and to identify areas of concern, 2) careful siting of renewable energy projects to avoid loss of important habitat, 3) designing new military training sites on Fort Irwin to minimize significant impacts, and 4) prioritizing the protection of high quality habitat in areas on the northern parts of the range where winter rainfall is more likely to be adequate in the future. 
It would be particularly useful to document the current status of Mohave ground squirrel populations on public lands south of Ridgecrest toward Red Mountain. Camera studies in 2011-2012 detected the species at a number of sites in this region (Leitner and Delaney 2014), but there are no recent data. A repeat of the 2011-2012 camera study would be desirable. Except for the long-term Coso study sites, there have been no systematic surveys on the North Range of China Lake. A large-scale camera survey there would provide important data and could be done without disruption of military testing operations. The 2019 camera study on the China Lake South Range suggested that MGS are absent from much of this region. There are plans to carry out a similar survey at other sites on this large military reservation, which should greatly increase our understanding of the Mohave ground squirrel distribution here.

Careful siting of renewable energy projects within the Mohave ground squirrel range can minimize their impacts. Large-scale solar projects on private land should focus on areas where Mohave ground squirrels are no longer present or on previously disturbed sites. It would be desirable to design large solar arrays to retain vegetation cover so that Mohave ground squirrels could more easily move through them. The North of Kramer and Haiwee DFAs on BLM lands appear to support viable populations, whereas there is a minimal amount of suitable Mohave ground squirrel habitat on the Searles DFA.

Fort Irwin is currently planning to initiate military training on the WTA, an area that is known to support an important population. It would desirable to gain a better understanding of the extent of Mohave ground squirrel occurrence in different parts of this large area. With that knowledge, it should be possible to site high-intensity training to avoid the most serious impacts.

Climate change with increasing temperatures and diminishing winter rainfall can be expected to continue to impact the Mohave ground squirrel range in the western Mojave Desert. It seems reasonable that higher elevation and more northerly parts of the range will be most likely to continue to receive adequate rainfall for reproduction. It is also possible that Mohave ground squirrels may respond to climate change by extending their range northward into Owens Valley. Conservation efforts should focus on protecting all potential climate refugia from additional human impact.

There is concern that the round-tailed ground squirrel is expanding into significant areas along the eastern edge of the Mohave ground squirrel range. The round-tailed ground squirrel is widely distributed in the eastern California deserts and into Arizona. It appears to be well-adapted to disturbed habitats and to drier and warmer conditions. This species may be expected to continue to encroach on parts of the Mohave ground squirrel range at lower elevations and where significant anthropogenic disturbance has occurred.

\section{ACKNOWLEDGMENTS}

The preparation of this review was funded by the CDFW. Several field studies supported by BLM and CDFW have contributed much-needed distributional data. I am very grateful to the many desert biologists who have provided records of their field activities. K. Cripe was responsible for production of the many maps. S. Phillips and Vernadero Group Inc. contributed GIS data for preparation of maps. Natural resource staff at China Lake, EAFB, and Fort Irwin were extremely helpful in providing information about Mohave ground squirrel occurrence on their installations. Finally, I would like to thank S. Osborn for his leadership on Mohave ground squirrel conservation and for encouraging me to prepare this paper. 


\section{LITERATURE CITED}

Best, T. L. 1995. Spermophilus mohavensis. Mammalian Species 509:1-7.

California Department of Fish and Game (CDFG). 2003 (minor revisions 2010). Mohave Ground Squirrel Survey Guidelines. California Department of Fish and Game. Sacramento, CA, USA.

California Department of Fish and Wildlife (CDFW). 2019. A Conservation Strategy for the Mohave Ground Squirrel, Xerospermophilus mohavensis. Sacramento, CA, USA.

Ernest, K. A., and M. A. Mares. 1987. Spermophilus tereticaudus. Mammalian Species 274:1-9.

Harris, J. H., and P. Leitner. 2004. Home-range size and use of space by adult Mohave ground squirrels, Spermophilus mohavensis. Journal of Mammalogy 85:517-523.

Iknayan, K. J., and S. R. Beissinger. 2018. Collapse of a desert bird community over the past century driven by climate change. Proceedings of the National Academy of Sciences 115:8597-8602.

Inman, R. D., T. C. Esque, K. E. Nussear, P. Leitner, M. D. Matocq, P. J. Weisberg, T. E. Dilts, and A. G. Vandergast. 2013. Is there room for all of us? Renewable energy and Xerospermophilus mohavensis. Endangered Species Research 20:1-18.

Inman, R. D., T. C. Esque, K. E. Nussear, P. Leitner, M. D. Matocq, P. J. Weisberg, and T. E. Dilts. 2016. Impacts of climate change and renewable energy development on habitat of an endemic squirrel, Xerospermophilus mohavensis, in the Mojave Desert, USA. Biological Conservation 200:112-121.

Krzysik, A. J. 1994. The Mohave Ground Squirrel at Fort Irwin, California: A State Threatened Species. US Army Construction Engineering Research Laboratories, Technical Report EN-94/09, Champaign, IL, USA.

Leitner, B. M., and P. Leitner. 2017. Diet of the Mohave ground squirrel (Xerospermophilus mohavensis) in relation to season and rainfall. Western North American Naturalist 77:1-13.

Leitner, P. 2008. Current status of the Mohave ground squirrel. Transactions of the Western Section of The Wildlife Society 44:11-29.

Leitner, P. 2010. Exploratory trapping surveys for the Mohave ground squirrel in three regions of the western Mojave Desert 2002. Nongame Wildlife Program Report 2010-2. Prepared for California Department of Fish and Game, Wildlife Branch, Sacramento, CA and Inland Deserts Region, Ontario, CA, USA.

Leitner, P. 2014. Mohave ground squirrel camera study 2013. Prepared for California Department of Fish and Wildlife, Inland Deserts Region, Ontario, CA, USA.

Leitner, P. 2015. Current status of the Mohave Ground Squirrel (Xerospermophilus mohavensis): A five-year update (2008-2012). Western Wildlife 2:9-22.

Leitner, P. 2019. Monitoring Mohave ground squirrel populations in the Coso region, Inyo County. Prepared for California Department of Fish and Wildlife, Inland Deserts Region, Ontario, CA, USA.

Leitner, P. 2020. Monitoring Mohave ground squirrel populations on BLM lands in the California desert. Prepared for Bureau of Land Management, California State Office, Sacramento, CA, USA.

Leitner, P. and D. K. Delaney. 2014. Mohave ground squirrel camera study 2011-2012. Prepared for California Department of Fish and Wildlife, Sacramento, CA, USA. 
Leitner, P. and D. K. Delaney. 2015. Mohave ground squirrel camera study 2014: Surveys west of California City. Prepared for California Department of Fish and Wildlife, Sacramento, CA, USA.

Leitner, P., J. Rippert, and M. D. Matocq. 2017. Genetic structure across a contact zone between Xerospermophilus ground squirrels in southern California. Western North American Naturalist 77:152-161.

Lopez, J. D., and N. Tautfest. 2019. Edwards Air Force Base Mohave Ground Squirrel Cumulative Project Summary Report (PA20338). Redhorse Corporation, San Diego, CA, USA.

Scarry, P. L., P. Leitner, and B. M. Leitner. 1996. Mohave Ground Squirrel Study in West Mojave Coordinated Management Plan Core Reserves, Kern and San Bernardino, May-June 1994 and April-May 1995. Prepared for California Department of Fish and Game, Region 4, Fresno, CA, USA.

U.S. Bureau of Land Management (BLM). 2016. Desert Renewable Energy Conservation Plan. Available from: https://www.blm.gov/programs/planning-and-nepa/plansin-development/california/desert-renewable-energy-conservation-plan. Accessed 14 Sep 2020.

Vernadero Group Incorporated. 2019. Mohave Ground Squirrel Camera Survey at Naval Air Weapons Station China Lake, California. Final Report. Prepared by Vernadero for Naval Facilities Engineering Command Southwest and Naval Air Weapons Station China Lake.

Wessman, E. V. 1977. The distribution and habitat preferences of the Mohave Ground Squirrel in the southeastern portion of its range. California Department of Fish and Game, Wildlife Management Branch Administrative Report 77-5.

Williams, A. P., E. R. Cook, J. E. Smerdon, B. I. Cook, J. T. Abatzoglu, K. Bolles, S. H. Baek, A. M. Badger, and B. Livneh. 2020. Large contribution from anthropogenic warming to an emerging North American megadrought. Science 368:314-318.

Submitted 29 September 2020

Accepted 17 November 2020

Associate Editor was M. Mantor 